\title{
Correction to: Variation in Blood and Colorectal Epithelia's Key Trace Elements Along with Expression of Mismatch Repair Proteins from Localized and Metastatic Colorectal Cancer Patients
}

\author{
Ali Ghorbani Ranjbary ${ }^{1} \cdot$ Jalil Mehrzad ${ }^{1,2} \cdot$ Hesam Dehghani ${ }^{3,4} \cdot$ Abbas Abdollahi $^{5} \cdot$ Saman Hosseinkhanin $^{6}$ \\ Published online: 22 October 2020 \\ (C) Springer Science+Business Media, LLC, part of Springer Nature 2020
}

Correction to: Biological Trace Element Research https://doi.org/10.1007/s12011-019-01749-9

The original version of this article unfortunately contained a mistake. The author Jalil Mehrzad should also be affiliated with "Department of Pathobiology, Section Biotechnology, Faculty of Veterinary Medicine, and Institute of Biotechnology, Ferdowsi University of Mashhad, Mashhad, Iran”. The email address mehrzad@um.ac.ir is also added.

Publisher's Note Springer Nature remains neutral with regard to jurisdictional claims in published maps and institutional affiliations.

The online version of the original article can be found at https://doi.org/ 10.1007/s12011-019-01749-9

Jalil Mehrzad

mehrzad@ut.ac.ir; mehrzad@um.ac.ir

1 Department of Pathobiology, Section Biotechnology, Faculty of Veterinary Medicine, and Institute of Biotechnology, Ferdowsi University of Mashhad, Mashhad, Iran

2 Department of Microbiology and Immunology, Faculty of Veterinary Medicine, University of Tehran, Tehran, Iran

3 Department of Basic Sciences, Faculty of Veterinary Medicine, Ferdowsi University of Mashhad, Mashhad, Iran

4 Stem Cells and Regenerative Medicine Research Group, Research Institute of Biotechnology, Ferdowsi University of Mashhad, Mashhad, Iran

5 Surgical Oncology Research Center, Mashhad University of Medical Sciences, Mashhad, Iran

6 Department of Biochemistry, Faculty of Biological Sciences, Tarbiat Modares University, Tehran, Iran 